This item was submitted to Loughborough's Research Repository by the author.

Items in Figshare are protected by copyright, with all rights reserved, unless otherwise indicated.

\title{
Behaviour and the safety of older people on stairs
}

PLEASE CITE THE PUBLISHED VERSION

http://www.crcpress.com/product/isbn/9780415256360

\section{PUBLISHER}

(C) Taylor \& Francis, CRC Press

\section{VERSION}

AM (Accepted Manuscript)

\section{LICENCE}

CC BY-NC-ND 4.0

\section{REPOSITORY RECORD}

Haslam, Roger, Denise Hill, Joanne E. Sloane, Peter A. Howarth, and Katherine S.F. Brooke-Wavell. 2019. "Behaviour and the Safety of Older People on Stairs". figshare. https://hdl.handle.net/2134/12503. 
This item was submitted to Loughborough's Institutional Repository (https://dspace.lboro.ac.uk/) by the author and is made available under the following Creative Commons Licence conditions.

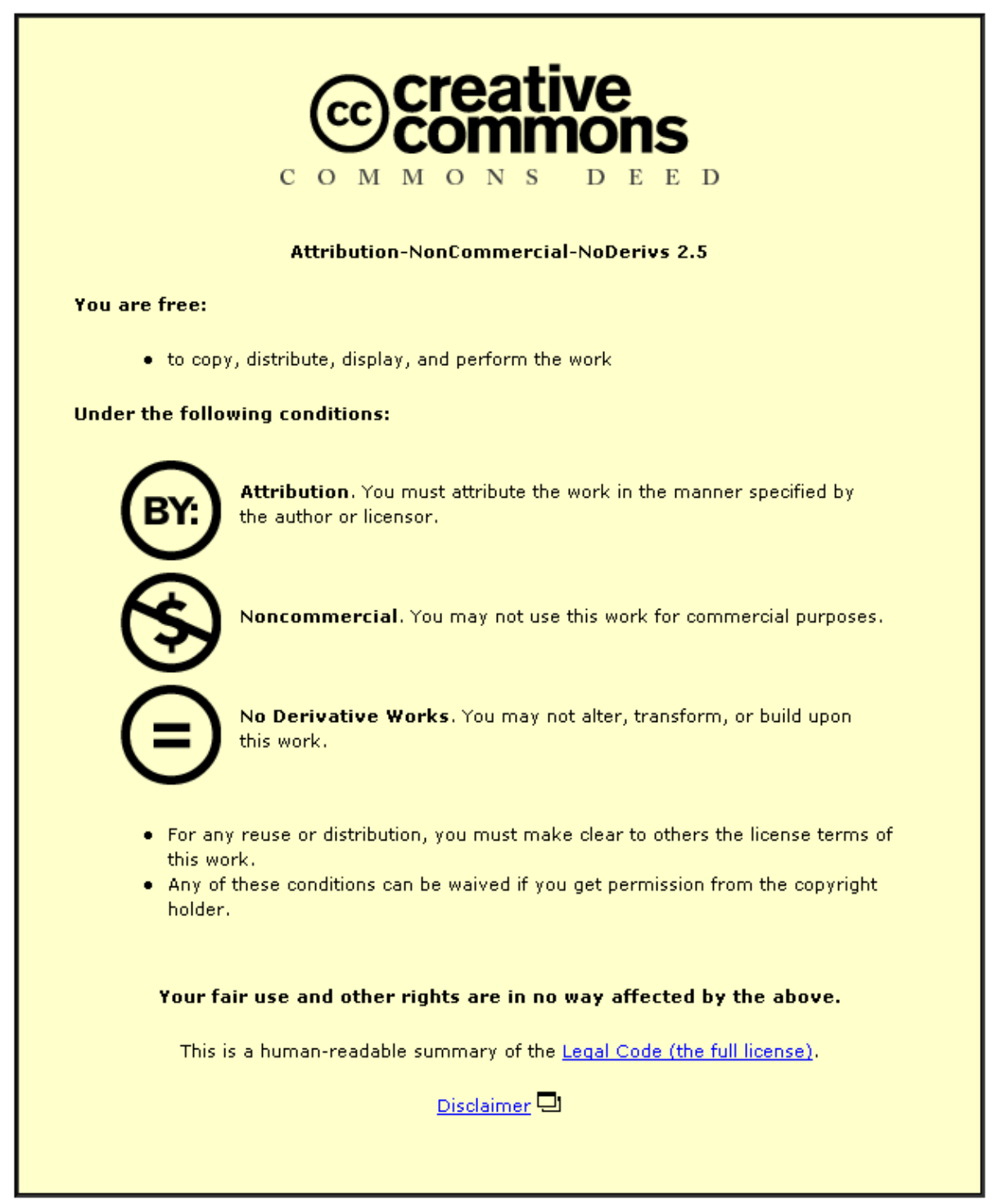

For the full text of this licence, please go to: http://creativecommons.org/licenses/by-nc-nd/2.5/ 


\title{
Chapter 11 Behaviour and the safety of older people on stairs
}

\author{
Roger Haslam, Denise Hill, Joanne Sloane, \\ Peter Howarth, Katherine Brooke-Wavell
}

\section{7/3/05}

\subsection{Introduction}

As described in chapter 5, older people have an increasing vulnerability to falling, to the extent that 1 in 3 adults aged over 65, and nearly half of those over 80, fall each year (Prudham and Evans, 1981). Approximately half of all recorded fall episodes occurring among independent community dwelling older people happen in their homes and immediate home environments (Lord et al, 1993). Estimates for the UK, based on the Home Accident Surveillance System (HASS), indicated that 373,000 older people in the UK received injuries from a fall in the home in 2002, severe enough to require attendance at a hospital accident and emergency department (DTI, 2003). Within these figures, older people falling on stairs in the home is a significant category, resulting in excess of 500 deaths and 51,000 hospital casualty department attendances each year. These statistics do not include patients seeing their GP or those not seeking treatment. A similar pattern exists in the USA (Startzell, 2000). Worldwide, it has been argued that falls on stairs rival road accidents as a leading cause of accidental injury and death (Pauls, 1991; Templer, 1992). 
Although there is general agreement that older users are at increased risk of falling on stairs than younger adults, the extent of this is difficult to quantify due to the absence of data on stair usage by different age groups (Templer, 1992). When older individuals do fall on stairs, their injuries tend to be more serious, with fractures more common (Pauls, 1985; Nagata, 1993). The cost to health services of treating these patients is substantial. Falls also have serious psychological and social consequences for older people, affecting mobility, confidence and quality of life (Delbaere et al, 2004).

Personal factors contributing to fall accidents among older people are well known and include decreased balance ability, disturbed gait, cognitive impairment, reduced strength and vision, illness, and side effects from use of medication (eg Bath and Morgan, 1999; Startzell et al, 2000; Lord et al, 2001; Masud and Morris, 2001; Tinetti et al, 1988). In the past, environmental aspects have been estimated as a primary cause in fall accidents in the older population in around $1 / 3$ of cases (Smith, 1990), although more recent studies have not been able to isolate these as a major risk factor independent of other causes (Lord et al, chapter 5). Environmental features identified by stair accident investigations for falls involving adults (of all ages) include poor condition of stair surface, objects on stairs, risers too high or too low, narrow goings, absent or poorly designed hand rails, and poor lighting (Templer, 1992; Roys, chapter 3).

Dowswell et al (1999) suggested that falls among the 'young elderly' (65-74) are more likely to involve environmental factors, while personal factors are more important in the 'oldest' age group (those aged 85 and over). This notion is compatible with the model described by Lord et al (2001), where the risk of falling varies according to the interaction between an 
individual's physical ability and the demands of the environment. Those with declining physical abilities will be affected increasingly by environmental challenges.

Behaviour, especially when coupled with inadequacies of the surroundings or personal frailty, has been suggested as playing a large part in many falls on stairs (Templer, 1992). And it seems reasonable to expect that behaviour will be a mediating influence in the interaction between individual abilities and environmental challenges (Connell and Wolf, 1997). In the case of stairs, this might involve either the manner of stair use, or actions which affect the stair environment. For example, it has been suggested that older people may be less able to maintain their stairs in good repair (Healy and Yarrow, 1998).

In view of the likely influence of behaviour on risk of falling, it is surprising that there has been only limited research concerning the contribution of this to falls among the older age group (Askham et al, 1990; Connell and Wolf, 1997). The study reported in this chapter addressed this problem, investigating how older people use their stairs, why they use them the way that they do, and circumstances likely to affect risk of falling.

\subsection{Preliminary focus groups}

An initial qualitative investigation, reported elsewhere (Haslam et al, 2001), used focus groups to examine older people's knowledge of safety on stairs. It was apparent from the focus groups that use of stairs does become more difficult with increasing frailty, leading to avoidance in some cases. The location of essential facilities in some homes, eg the lavatory, may necessitate increased use of stairs for certain individuals. The focus group participants offered intuitive observations of situations and circumstances where risk of falling on stairs might be increased, such as leaving objects on stairs, hurrying on stairs, using stairs in the 
dark, and carrying items, although they reported that they continued to engage in these despite concerns about safety. In this respect, safety implications from features of the environment appeared to be more readily identified than risks from behaviour. Cleaning stairs can present problems due to difficulties with access or a need to use heavy and awkward equipment. The focus group participants generally recognised that medication and use of alcohol may increase risk of falling, but individuals might not appreciate fully when they personally are at increased risk. Discussion within the groups described situations in which bifocal and varifocal spectacles may affect vision and balance on stairs (see also chapter 4). Most of the study participants indicated that they had given only limited thought to stair safety prior to the focus groups.

\subsection{Home interview survey}

Building on the focus groups, interviews were conducted with 157 older people living in their own homes, to collect detailed quantitative information on stair use and factors influencing this. Participants were recruited on a convenience basis from the counties of Nottinghamshire and Leicestershire, using a combination of direct and indirect contact. Sampling was on a quota basis, according to age and gender, using estimated population figures for the UK (ONS, 1991). Likewise, house type was a sampling dimension, based on national estimates of housing stock with respect to age and type of dwelling (Survey of English Housing, 1998). Socio-economic class was assessed using postcode analysis (against data provided by Experian).

At the beginning of each interview participants received an explanation of the purpose of the study and what the interview would entail. The interviews followed the format given in table 11.1, with each interview lasting approximately 2 hours. Loughborough University Ethical 
Advisory Committee approval was obtained prior to commencing the research. Statistical analysis used $\mathrm{Chi}^{2}$ tests for cross-tabulation relationships and Pearson and Spearman correlation coefficients for assessing interval/ordinal data associations, as appropriate. Qualitative data interpretation was also used in conjunction with quantitative analysis.

table 11.1 about here

\subsection{Home interview survey results}

A total of 157 participants were interviewed for the survey. The majority of these took place on an individual basis, although interviews with 14 married couples were undertaken with both partners present. Consequently 150 households were visited in total.

\subsubsection{Participant and housing details}

Details of participants are presented in table 11.2. In order to assess the effects of age, the participants were split into three age groups: 'youngest' (65-74), 'middle' (75-84) and 'oldest' ( 85 and over). In terms of data on their physical capability, as might be expected, Modified 'Modified Barthel Index' (MMBI) scores indicated reduced functional ability in the oldest age group (aged 85 and over). There was no difference in MMBI score with gender. The 'oldest' participants also experienced more difficulty with the 'rise from stool' test $(p<0,001)$. The grip strength of the youngest age group in the study (the only age group for which comparison data are available) was slightly lower than recorded by the Allied Dunbar (1992) National Fitness Study. Allied Dunbar reported mean values of $360 \mathrm{~N}$ for men and $220 \mathrm{~N}$ for women aged $65-74$, versus $349 \mathrm{~N}$ and $214 \mathrm{~N}$ respectively for our participants in this age range. 
Details of housing characteristics and stair handrail provision are given in tables 11.3 and 11.4. A pitch of $42^{\circ}$ is the maximum steepness permitted for private stairs by the Building Regulations in the UK. All the houses built within the last 30 years had a stair pitch less than $42^{\circ}$, with older houses tending to have stairs steeper than $42^{\circ}(p<0.001)$. Among the households with 2 handrails, the second had been fitted on the advice of a community occupational therapist or social services advisor on $28 \%$ of occasions. For $37 \%$ of participants, the suggestion originated from family or friends, with the remainder $(35 \%)$ stating that it was their own idea. Although many participants with a single handrail fitted to their stairs said they thought they would benefit from another handrail in the future $(23 \%)$, this does not necessarily mean they will proceed to obtain one. Participants cited various problems as deterring them from obtaining a second rail, including the expense and knowing whom to approach to assist with installation.

In $41 \%$ of households, windows were positioned part way over the landing or completely over stairs. Where windows were in these positions, a number of participants reported difficulty accessing the window to clean it $(27 \%)$, open it $(20 \%)$ or to change curtains $(26 \%)$. Problems arise due to both the position of windows and the functional ability of the individual. The older the age group the more likely it was that participants had problems cleaning the landing window $(\mathrm{p}<0.01)$, opening the window $(\mathrm{p}<0.05)$ and changing the curtains at the window $(\mathrm{p}<0.001)$

tables 11.3 and 11.4 about here 


\subsubsection{Use of stairs}

When asked about their use of stairs, $32 \%$ of interviewees reported that they avoid using stairs wherever possible, with the 'oldest' age group using stairs less frequently than the 'youngest' and the 'middle' age groups $(\mathrm{p}<0.01)$. There were no reported differences in frequency of stair use for 'fallers' and 'non-fallers' in the sample or between those living with others or living alone. Most interviewees (89\%) identified hurrying on stairs as a factor that would increase risk of falling. However, $63 \%$ stated that they do hurry on occasions, giving various reasons for this (multiple responses): answering a caller at the door (38\%), answering the telephone (27\%), retrieving items left upstairs (23\%), and needing to use an upstairs toilet (13\%). A sizeable proportion of participants (37\%) said that they made a point of not hurrying for any reason. The older the participant the less likely they were to hurry $(\mathrm{p}<0.001)$.

A large proportion of participants (92\%) considered that carrying objects either up or down stairs could be hazardous, although only a small number $(5 \%, n=8)$, the majority of whom $(n=6)$ were aged 75 and over, indicated explicitly that they no longer attempt to carry anything up or down stairs. Many participants mentioned strategies they employ to improve their safety when carrying objects up and down stairs, such as moving more slowly, resting items on steps and moving up or down a few steps at a time, and throwing items down to the bottom of the stairs. Some $29 \%$ of participants reported that when needing to move an object up or down stairs that may cause them a problem, they would not ask for help but 'have a go anyway'.

When asked about the frequency of use of handrails, $72 \%$ reported that they use handrails every time they use their stairs. In households with two handrails fitted, $74 \%$ of participants 
stated that they use both of these. Of those participants whose house had one handrail, 24\% said that they had considered having a second fitted. Of those who had not considered it, when asked, $17 \%$ thought that they would eventually need one.

In response to questions about use of stair lighting, $68 \%$ indicated that they avoid using stair lights during the day, with $18 \%$ stating that they do not switch the stair lights on if they need to get up and use the stairs during the night. Cost was mentioned by $11 \%$ of participants as a reason that they use lights to a minimum. This was in the context of $61 \%$ of households having illumination levels below the level of 50 lux during the day, where use of lighting would be recommended. Table 11.5 presents information on stair lighting and various other researcher observations regarding the stair environment.

In terms of items left on stairs, permanent objects were more likely to be positioned on stairs in detached houses, and temporary objects were seen more often on stairs in smaller terraced homes $(p<0.001)$. Examples of items seen on stairs are shown in figures 11.1 and 11.2. When asked, $89 \%$ of participants identified leaving objects on stairs as a factor that would increase the risk of falling. However, a large proportion of participants $(71 \%)$ reported that they do place objects on stairs. There was considerable overlap between those identifying this as a risk factor and those engaging in the practice $(\mathrm{p}<0.01)$. When asked whether their stair covering was in need of repair, $8 \%$ reported that it was. However, on inspection by the interviewer, $29 \%$ of the coverings were judged to be either worn, frayed or poorly fitted.

table 11.5 about here 
No differences were found with the social class of the participants, or with the tenure of the dwelling, in the proportions of households with poor stair coverings. Nor were there any differences between participants of different social class, or with different visual acuity, in the presence of loose mats or rugs at the top of stairs. However, it must be noted that the sample size for this analysis was small. It is also noteworthy that no one in the 'oldest' age group had a rug or loose mat positioned at the top of stairs. Coverings in households where stairs are steep tended to show more signs of wear, although this difference was not statistically significant. In some instances heavily patterned carpets were found which make it difficult to distinguish step edges, eg figure 11.3a compared with 11.3b.

figure 11.3 about here

In a small number of households $(3 \%, \mathrm{n}=5)$ mirrors were found positioned on half-landings or close to the top of stairs, which might present a visual distraction (figure 11.2). In some other homes $(6 \%, n=9)$ stair lifts had been fitted along the length of the flight reducing the width for other stair users.

Two-thirds of interviewees (66\%) reported that they clean their stairs themselves, with 36\% using a full-sized vacuum cleaner to do this. Proportionally more of the 'oldest' age group chose to use a small hand-held vacuum cleaner, or do not clean the stairs themselves $(\mathrm{p}<0.001)$. Of those who do clean their stairs, a majority $(55 \%)$ reported doing so in the direction of top to bottom, moving down backwards. Some $35 \%$ of the group who do their own cleaning identified various aspects of vacuum cleaner use as problems they thought would increase risk of falling. 
Responses to questions concerning improvements made to the stair environment over the previous 5 years to make them safer found that $17 \%$ of households had installed a second handrail, while $16 \%$ had replaced the floor covering. Other changes reported by interviewees included: using brighter light bulbs, fitting more transparent lampshades, use of low energy light bulbs, and painting the walls a lighter colour, but in each of these cases, $5 \%$ or fewer of households had made the change.

\subsubsection{Interviewee health and experience of falls}

Visual acuity was tested at a distance of 2.5 metres, with scores converted to conventional Snellen notation (Howarth and Bullimore, 2005). Vision of $6 / 12$ is considered adequate for most everyday tasks, while in the UK, the requirement for driving is approximately $6 / 15$ or better. A high proportion of participants (68\%) had uncorrected visual acuity worse than $6 / 12$, with $19 \%$ of participants having corrected visual acuity worse than this. There were no significant differences between interviewees with and without history of falling on stairs with respect to their visual acuity. Visual stereopsis, one component of the depth perception process was assessed using a Frisby stereotest (Frisby, 1980). The results from this indicated that $50 \%$ were unable to detect the depth to a pattern with uncorrected vision, while $25 \%$ were unable to detect depth with vision corrected. There were no significant differences between participants with and without history of falling on stairs with respect to visual stereopsis.

Almost all (99\%) of the sample reported using spectacles, with over half (57\%) having bifocal glasses. A number of participants (16\%) reported that their spectacles (all types) cause them visual problems when using stairs. These problems included an inability to judge depth (and consequent uncertainty in the location of steps) and distortion of the steps when using bifocal 
spectacles. However, many bifocal wearers $(80 \%)$ reported that they did not experience any of these problems. Some $27 \%$ of spectacle wearers reported not wearing their glasses when needing to get up during the night.

As might be expected among this age group, use of prescribed medication was high (table $11.6)$, with $16 \%$ of the sample reporting effects from their use of medicines that could affect risk of falling. A relationship was found between gender and the reporting of alcohol drunk in the previous 7 days before the interview, with $77 \%$ of men as opposed to $57 \%$ of women reporting having done so $(\mathrm{p}<0.05)$. In addition, there was a difference with only $30 \%$ of men, compared with $53 \%$ of women, reporting avoiding alcohol whilst taking prescribed medication $(\mathrm{p}<0.05)$. Although not prompted during the interview, a number of participants $(10 \%)$ specifically mentioned using stairs as a form of daily exercise.

table 11.6 about here

Details of interviewees' experience of falling on either their own stairs or those in the homes of relatives are given in table 11.7. No statistical relationship was found between the measures of functional ability (including age) and experience of falling on stairs. A positive association was found between experience of falling on stairs and taking 4 or more prescribed medications daily $(\mathrm{p}<0.05)$ and problems holding onto the handrail (due to either design of rail or personal factors $)(\mathrm{p}<0.05)$.

table 11.7 about here 
Approaching $1 / 3$ of participants (28\%) said they were concerned about falling on stairs, although $90 \%$ of participants rated their stairs as being safe, when asked about this separately. The majority of participants felt that their stairs were safe, regardless of their MMBI functional ability score or their ability to perform the 'rise from stool' test.

At the conclusion of the interview, participants were asked if they had ever received any advice about safety on stairs. Among the respondents, $13 \%$ indicated that they had, most often (7\%) from an Occupational Therapist or Physiotherapist, with 7\% having found the advice given to them useful. There were no statistically significant associations between those having received advice on stair safety and previous experience of falls. This was also the case for the indicators of physical capability (MMBI, grip strength and rise from stool test).

\subsection{Discussion}

This study explored how study participants use their stairs and how this is influenced by individual circumstances and behaviour. The results confirm that stair use does present a difficulty for a sizeable proportion of older people and indicate how the decisions and actions of this group affect their risk of falling in this location.

\subsubsection{Interviewee fall experience}

With $30 \%$ of the sample having fallen on their stairs during the past 12 months, the frequency is perhaps higher than might be expected, taking into account prevalence of falling in all locations (Lord et al, chapter 3). This might indicate a sampling bias, with those having a reason to be interested in stair safety more likely to volunteer to participate in the research. If there were such a bias, then it is possible that interviewees might be more apprehensive about 
using stairs than the wider population of older people, be in worse physical condition or have less safe stair environments.

Among the variables examined for a relationship with falling, age, MMBI functional ability score, rise from stool test, visual acuity, and use of a walking aid were all found to be nonsignificant. Significant associations between falling on stairs and use of 4 or more prescribed medications $(\mathrm{p}<0.05)$ and problems holding onto the handrail $(\mathrm{p}<0.05)$, are both as might be expected. Other research has pointed to the possible involvement of footwear in falls on stairs (Startzell et al, 2000). In the present study, footwear was mentioned as an issue in $24 \%$ of the stair falls experienced by participants.

It is interesting that while those who had previously fallen on stairs rated themselves as being more likely to fall on stairs in the future $(\mathrm{p}<0.05)$, a very high proportion of this group regarded their stairs as safe $(87 \%)$. The implication of this is that those who have fallen on stairs have reduced confidence in their ability to use stairs safely for reasons other than the perceived safety of their particular stair environment.

\subsubsection{Stair environment}

The majority of dwellings in this study $(65 \%)$ had stairs steeper than the maximum allowed under current UK Building Regulations ( $42^{\circ}$ maximum pitch). Some participants commented that they find it necessary to descend stairs with their feet positioned sideways, due to the size of the tread being insufficient to accommodate the full size of their feet. The Building Regulations recommend a minimum going of $220 \mathrm{~mm}$ for private housing, which Roys (2001 and chapter 3 ) identified as smaller than the foot length of $95 \%$ of the adult population (or $100 \%$ if $30 \mathrm{~mm}$ is allowed for footwear). In the present study, the mean going of $214 \mathrm{~mm}$ was 
smaller than the minimum recommended. With average foot lengths of participants being $267 \mathrm{~mm}$ for men and $243 \mathrm{~mm}$ for women (unshod), it is clear that it is common for an individual's foot length to exceed the size of the steps on their stairs. Remedying this situation will be a long term proposition, requiring attention to building codes and standards.

There is wide agreement on the importance of appropriately designed and fitted handrails (Templer, 1992; Roys, chapter 3). To prevent a fall, the rail needs to be capable of taking the weight of a person when they pull on it. In a number of households visited during the survey $(10 \%)$, the handrail was judged to be in need of repair. A third of homes $(34 \%)$ had at some time had a second handrail fitted, a somewhat higher proportion than found by Edwards and Jones (1998). In their survey, less than $20 \%$ of individuals in a representative sample of persons aged 65 and over had an extra stair handrail installed as an assistive device. Generally, interviewees with a second rail fitted to the stairs in the present study had lower functional ability $(\mathrm{p}<0.05)$, suggesting that a need for additional support using stairs had been recognised. Interestingly, a high proportion of those with an additional handrail among Edwards and Jones' respondents (91\%), and in our study (74\%), reported using it, signifying that individuals find them beneficial. Interviewees often spoke favourably of the second rail, mentioning that it allowed them to use their stairs with increased confidence.

Although most participants reported their stair coverings to be in reasonable condition $(86 \%)$, on inspection by the researcher, many $(29 \%)$ were judged to be in need of replacement or repair. It seems likely that either the interviewees had a lower threshold for what constitutes reasonable condition, or else they had not noticed wear and tear that may have happened gradually over many years. Even if a householder is aware that a stair covering is in poor condition, there may be obstacles to having it replaced. These include the expense, difficulty 
involved in sourcing a replacement, disruption during fitting, or believing that awareness of any damage will be sufficient to avoid having an accident. Coverings in households where stairs are steep (ie the riser high and the going short) tended to show more signs of wear. In these circumstances, the shoe heel may come into frequent contact with the carpet on the leading edge of the tread or the top of the riser, resulting in premature wear.

The pattern and colour of carpets may make it difficult to detect step edges in some circumstances (figure 11.3a). Generally, coverings light in colour and non-patterned make steps more visible (figure 11.3b), whereas those that are heavily patterned tend to camouflage the edges of steps (Howarth, chapter 4). Part of this is due to the pattern making it difficult to judge depth and position, with patterns incorporating horizontal and vertical lines appearing to cause a particular problem (Cohn and Lasley, 1985 and 1990). These effects may be worse for those with poor visual acuity, poor visual stereopsis, or who do not wear their spectacles. Given the limited awareness of possible implications of colour and patterning, these issues are unlikely to be considered by older people when selecting stair carpets or other coverings for their home.

Poor lighting has been suggested as a contributory factor in many fall accidents (Templer, 1992), although precise lighting requirements are difficult to specify. Adequate lighting is necessary to see the steps on stairs and to detect objects. Moreover, dim lighting levels appear to be associated with poorer postural stability in older people (Brooke-Wavell et al, 2002). Light measurements taken during the day in participants' homes, with artificial lighting switched off, found $61 \%$ of households to have light levels of 50 lux or less. Recommendations for the workplace specify this level of illumination as appropriate for areas visited infrequently, requiring limited perception of detail (Howarth, 2005). In the present 
survey, many of the homes visited had light bulbs of less than $100 \mathrm{~W}$ fitted (44\%). Coupled with this, some households had lampshades of a design further restricting levels of lighting. A number of participants had low energy, low Wattage light bulbs at the top of stairs. This type of luminaire requires changing much less frequently than a traditional incandescent lamp, thereby reducing the possibility of falling when changing the bulb. A second advantage is reduced cost of operation, allowing people to leave stair lights on without the worry of large electricity bills. Cost was mentioned by $11 \%$ of participants as a reason that they use lighting to a minimum.

Although smoke alarms were not examined explicitly in the environmental survey, a number were seen positioned over the stairs. It these circumstances, it may be difficult for the householder to test the alarm or change the battery, without putting themselves at risk of falling. Guidance and standards for installation may be needed to address this problem.

Items placed on stairs can be a trip or slip hazard, or may form an injurious object to fall against. Objects may be positioned on stairs on a temporary or more permanent basis, with many instances of both found in the homes of participants in this study. The finding that items such as furniture were more likely to be positioned on stairs in larger, detached dwellings, and temporary objects were seen more often on stairs in terraced houses $(p<0.001)$, may reflect the availability of space. Stairways in larger houses are more likely to have halflandings of sufficient size to accommodate larger, permanent objects. Storage space may be restricted in smaller homes, necessitating more frequent movement of items between levels or use of stairs as an overspill storage area. There is potential for housing design to more adequately anticipate home occupiers' needs for storage and inclinations for furnishing, to address this problem. 


\subsubsection{Stair usage}

Half of all participants said that there is no particular time of day that they use their stairs more often than any other. Over a third (38\%) reported that the morning was the period of most frequent use, giving various reasons for this. Some individuals mentioned the effects of medication increasing the need to use the toilet in the mornings, this sometimes being urgent, making it necessary to hurry (one third of the households had only a single toilet upstairs). Other reasons given for using stairs more in the morning were to perform housework tasks or to get ready to go out.

As might be expected, individual functional ability affects stair use, with those with decreased ability using stairs less often. Of those who stated that they use stairs infrequently, respondents described conditions that affect their legs, (e.g. pain in knees or hips), or other medical problems that make it difficult for them to exert themselves (e.g. heart problems or breathlessness), as the reason for their stair avoidance. Perhaps surprisingly, this study found no indication of cohabitation affecting patterns of stair use, as has been suggested elsewhere (Smith et al, 1994). It might be expected that in some circumstances, a more mobile partner will use the stairs more frequently to assist a less able spouse.

Similarly to Startzell et al (2000), this study suggested that older people seem to use stairs with increased caution in some respects, while still engaging in other potentially dangerous behaviours, such as leaving objects on stairs. The discrepancy manifests itself with the majority of interviewees identifying hurrying on stairs, carrying items and leaving objects on stairs as likely to increase risk of falling, but with many continuing to engage in these activities. Almost a third of participants in the study (29\%), for example, said that they would still attempt to carry an object up or down stairs that might cause them difficulty. The 
findings from our focus group research (Haslam et al, 2001) suggested that while individuals recognise certain activities as hazardous, they continue to practise them through perceived necessity and a view that the manner in which they personally carry out the function reduces any risk to an acceptable level. A desire to maintain independence, or a lack of access to someone able to provide assistance, are further possible explanations. Given the evidence from other research (Templer, 1992) that this conduct does increase risk of falling on stairs, there would appear to be a need to raise risk awareness and the potential consequences.

With regard to use of lighting (as opposed to provision of lighting as discussed in section 11.5.2), there was a conflict between recognition of the importance of good stair lighting and the low usage of supplementary lighting in practice $(68 \%$ not using stair lights during the day and $30 \%$ generally using lighting to a minimum). Using stairs at night without switching on lighting seems undesirable from a safety perspective (Connell and Wolf, 1997), a point which most interviewees recognised. Almost one fifth of interviewees (18\%), however, reported not switching on lighting, should they need to use their stairs after retiring to bed. A variety of explanations were given for this, including not wanting to disturb a sleeping partner, presence of sufficient illumination from outside, eyes already adapted to the dark, and individuals being familiar with their own stairs. When night illumination readings were taken in a selection of households, levels were unmeasurable with lights switched off. Howarth (chapter 4) describes how visual performance is reduced in such conditions. Although the need for education seems obvious in this respect, there might also be design solutions that would improve safety. For example, there may be benefit from the provision of lighting around stair areas, activated by movement, gradually increasing to an optimum level. Clearly, the technology would need to be of adequate sophistication to be acceptable to home occupiers and research involving users would be needed to achieve this. 
Cleaning on and around stairs appears to present particular problems, due to a combination of difficult access (eg landing windows) or the need to use awkward and heavy equipment (vacuum cleaners in particular). Some older people seem to reach a point where reduced strength and flexibility lead them to seek alternative methods, such as using smaller, handheld, battery operated vacuum cleaners, or employing a relative or another person to clean on their behalf. However, it seems plausible that some individuals will pass through a stage prior to this, where they struggle to clean as in the past, not accounting for their changing abilities, placing themselves at increased risk as a consequence. The challenge then is to encourage older people to appreciate their limitations, without instilling negative attitudes. Again, there is the possibility for improved design to facilitate cleaning. In one extreme example found in the household survey, a window was installed over an open stairwell (figure 11.4). The participant gave the following description of how she gained access to clean and change the curtains "I have to place planks of wood from the upper banister to the window sill and then walk across to the window. I don't feel at all secure when I do this." Connell and Wolf (1997) reported similar examples of older individuals engaging in hazardous activity, that would require a very high level of physical ability to do so safely.

figure 11.4 about here

\subsubsection{Individual capability}

The age profile of the sample of older people participating in the survey was similar to the distribution for those aged 65 and over in the UK. Apart from the possible implications of the sample recruitment (section 11.5.1), there is no evidence that the sample was atypical of the general population in any other systematic respect. 
Use of prescribed medication and alcohol, either alone or in combination can affect reaction time, balance and judgement. This applies particularly to psychotropic medication, ie as used to treat conditions such as anxiety, depression and insomnia (AGS, 2001). The high rate of use of prescribed medication in the survey, with $82 \%$ of those interviewed taking at least one medication daily and $26 \%$ taking 4 or more, is not unusual amongst those aged 65 and over (Cumming et al, 1991). Neither are the unwanted side-effects, such as drowsiness, dizziness or effects on vision reported by $16 \%$ of respondents. Indeed, improved prescribing has been highlighted as an important measures for fall reduction among older people (AGS, 2001; NICE, 2004).

Again, the widespread use of alcohol reflects general societal behaviour. Of course, it requires a certain level of alcohol imbibition to affect risk of falling, although few studies have sought to quantify this, nor considered any differences that might arise with ageing. Over a third (38\%) of participants reported drinking alcohol when taking prescribed medication, giving reasons such as not drinking enough to affect their medication, or waiting for a time after taking medication before consuming any alcohol. A significant proportion of the sample, at least one third, said that they had not received any advice from their doctor or pharmacist in this respect.

It seems there may be scope to improve individuals' knowledge of when they personally could be at increased risk of falling due to medication, or through mixing this with alcohol. This might be achieved through improved communication of medicine information to older people and their carers, regarding use and possible side effects, and by raising awareness of 
the extent to which alcohol consumption may contribute to falls among this age group (Wright and Whyley, 1994).

Almost all (99\%) of the sample reported using spectacles, with assessment of vision confirming the need for this. Even when wearing spectacles, 19\% of participants had corrected visual acuity less than $6 / 12$, a level considered adequate for everyday tasks. The loss of stereopsis, indicated by the $25 \%$ of the sample unable to detect depth to a pattern with corrected vision ( $50 \%$ with vision uncorrected), may impair the negotiation of stairs (Haegerstrom-Portnoy et al, 1999). Although it is not possible to draw definitive conclusions that deteriorating vision is a contributory factor in falls on stairs, it seems likely that this will be the case (Startzell et al, 2000), especially when negotiating unlit stairs at night, without using spectacles $(27 \%$ of participants reported not wearing their spectacles when moving around their home during the night).

A research question raised by this study is the extent to which bifocal and varifocal spectacles might be a contributory factor in falls on stairs? Of participants who wore bifocal spectacles, $20 \%$ reported that these caused problems when descending stairs. Problems included distortion and difficulty judging depth, with consequent uncertainty locating steps. A subsequent study by Davies et al (2001), examining records in a pre-existing injury database, found a significant association between falls on stairs, where the first event was the missed edge of a step and the wearing of bifocals or multifocal lenses.

Various methods were reported as used to reduce problems from wearing bifocals when descending stairs, such as positioning the head so that the wearer is not looking through the 
portion of the lens causing the visual distortion; not looking at the steps, but looking ahead to the bottom of the stairs; and not wearing glasses at all when using stairs.

Some participants $(27 \%)$ reported that they had been warned by their Optician or Optometrist of the need for care when using stairs and, for stronger prescriptions, the distorting effects on vision are readily apparent. Participants mentioned that they adapted to wearing bifocals, reporting that single steps and street curbs cause them the most problems subsequently. However, whether this compensatory behaviour actually occurs and, if so, whether it is sufficient to prevent falls is unknown.

The role of exercise in improving strength and fitness among older people has been established by several studies (Lord et al, chapter 5), and individually tailored exercise programmes have been shown to lead to a reduction in falls (Gillespie et al, 2003). Although information on exercise was not explicitly collected from interviewees during the present study, a small proportion of participants $(10 \%)$ indicated their view that using stairs could be beneficial in this respect. There were also accounts from interviewees of using stairs for this purpose, when perhaps their health might make this appear misguided. The pros and cons in this respect will vary from one individual to another.

While moving to a bungalow will inevitably reduce the risk of falling on stairs, it emerged from the focus group study that stairs and steps in shops or friends' homes may then become more difficult to negotiate. The term, 'bungalow legs' was used by one person to describe the difficulty and aches and pains experienced on stairs after a period of living in a holiday bungalow (Haslam et al, 2001). There may also be a psychological effect accompanying reduced stair use, leading to increased apprehension on the occasions on which they are used. 


\subsubsection{Awareness of risks}

While the study participants were often able to appreciate and understand situations that might increase risk of falling on stairs, they generally needed to have these brought to their attention first. This suggests that the risks are fairly evident, but not so evident that they will necessarily be noticed before a problem (fall or near miss) has occurred. This suggests a need for awareness raising. Unfortunately, only around one in ten of those interviewed were able to recall ever having been given any advice on stair safety $(13 \%)$, with half of these receiving guidance from an Occupational Therapist or Physiotherapist.

Anecdotal experience indicates that older people are willing to receive and accept advice, interested to learn how to minimise the likelihood of injuring themselves. This is supported by a strong desire to maintain independence and autonomy. Routes for education are many and approaches need to be tailored to different circumstances. It may be appropriate to begin the process at the time people retire, when most are still active enough to be able to make changes to the physical environment for themselves (Smith et al, 1994). As might be expected, personal experience, involving either the individual or a close associate, appears to have the strongest effect on perception of safety. It is also suggested that discussion or drama-based forums might prove a useful component of educational activities.

\subsection{Concluding discussion}

This investigation used focus groups and a home interview survey to examine patterns of stair use among older people and the presence of factors likely to affect risk of falling. Of particular interest was the influence of behaviour on exposure to fall risk. Similarly to Connell and Wolf (1997), the research demonstrates pathways through which the actions and decisions of older people affect their environment, themselves and the interaction between the 
two. Drawing together the evidence from the focus group and interview research, three routes are proposed through which the behaviour of older people influences their safety on stairs (figure 11.5):

1. behaviour involved in direct use of stairs

2. decisions and actions affecting the stair environment

3. behaviour affecting individual capability

figure 11.5 about here

It is argued that efforts aimed at reducing falls on stairs among older people should give attention to each of these three areas.

Relevant to this assertion, an American Geriatrics Society (AGS) led review, examining the efficacy of interventions aimed at preventing falls among older people, concluded that multifactorial interventions including a behavioural change component demonstrated benefit (AGS, 2001). There is no evidence, however, to support the use of behaviour modification approaches when used in isolation (AGS, 2001; and Gillespie et al, 2003), although this judgement is based on only a small number of studies. It should be recognised that attempts to change long established habits and routines, especially where there are a range of these to be targeted, presents a significant challenge (Connell and Wolf, 1997) and depends heavily on the mode of delivery. There appear to have been no studies which have examined explicitly the effectiveness of behavioural approaches to improving safety with regard to falls on stairs. Further research is desirable in both of these respects. The evidence on the value of attending to environmental hazards seems clearer, with several intervention evaluations including a 
substantial hazard modification component, reporting a reduction in falls (Gillespie et al, 2003).

Notwithstanding the findings from the various research studies, the recommendation from NICE (2004) that a participative approach should be taken, encouraging the involvement of older people in fall prevention programmes, is appealing. There is an empowering role for older people and their careers in assuming responsibility for making their environment safer and developing their individual capability. Other groups also have an important contribution to make with regard to safety on stairs. Medical and social advisors have a role in raising awareness of factors affecting stair safety and providing advice on what can be done to alleviate risks. Looking to the future, home designers have a responsibility for providing stairs which meet the requirements of older users and their differing needs and capabilities.

Although single strand approaches to prevention are necessary to collect evidence on the effectiveness of different fall prevention strategies, the appropriateness of this for wider practice is questionable. The other chapters in this book have demonstrated the manner in which falls arise from a complex interaction of circumstances. Falls are a multifactorial problem, requiring a multifactorial approach to prevention, especially among older people, where personnel factors are so heavily involved. 


\section{Acknowledgements}

This research was funded by the UK Department of Trade and Industry (DTI). Any opinions and conclusions expressed, however, are those of the authors alone and do not necessarily reflect DTI policy.

\section{References}

Allied Dunbar National Fitness Survey, 1992. A report on activity patterns and fitness levels: main findings (Sports Council and Health Education Authority: London).

American Geriatrics Society (AGS), British Geriatrics Society, and American Academy of Orthopaedic Surgeons Panel on Falls Prevention, 2001. Guideline for the prevention of falls in older persons. Journal of the American Geriatrics Society, 49, 664-672.

Askham J, Glucksman E, Owens P, Swift C, Tinker A and Yu G, 1990. A Review of Research on Falls Among Elderly People (Department of Trade and Industry: London).

Bath P A and Morgan K, 1999. Differential risk factor profiles for indoor and outdoor falls in older people living at home in Nottingham, UK. European Journal of Epidemiology, 15, $65-73$.

Brooke-Wavell K, Perrett L K, Howarth P A, Haslam R A, 2002. Influence of the visual environment on the postural stability in healthy older women. Gerontology, 48, 293-297. 
Cohn T E and Lasley D J, 1985. Visual depth illusion and falls in the elderly. Clinics in Geriatric Medicine, 1, 601-620.

Cohn T E and Lasley D J, 1990. Wallpaper illusion: cause of disorientation and falls on escalators. Perception, 19, 573-580.

Connell B R and Wolf S L, 1997. Environmental and behavioral circumstances associated with falls at home among healthy elderly individuals. Archives of Physical Medicine and Rehabilitation, 78, 179-186.

Cumming R G, Miller J P, Kelsey J L, Davis P, Arfken C L, Birge S J and Peck W A, 1991. Medications and multiple falls in elderly people: the St Louis OASIS study. Age Ageing, 20, $455-61$

Davies J C, Kemp G J, Stevens G, Frostick S P, and Manning D P, 2001. Bifocal/varifocal spectacles, lighting and missed-step accidents. Safety Science, 38, 211-226.

Delbaere K, Crombez G, Vanderstraeten G, Willems T and Cambier D, 2004. Fear-related avoidance of activities, falls and physical frailty: A prospective community-based cohort study. Age and Ageing, 33, 368-373.

Department of Trade and Industry (DTI), 2003. 24 ${ }^{\text {th }}$ (Final) Report of the Home and Leisure Accident Surveillance System (Department of Trade and Industry: London), DTI ref 03/32. 
Dowswell T, Towner E, Cryer C, Jarvis S, Edwards P and Lowe P, 1999. Accidental Falls:

Fatalities and Injuries - An Examination of the Data Sources and Review of the Literature on Preventative Strategies (Department of Trade and Industry: London), DTI ref 99/805.

Edwards N I and Jones D E. Ownership and use of assistive devices amongst older people in the community. Age and Aging, 27, 463-468.

Frisby J P, 1980. The Frisby stereotest: amended instructions. British Orthoptic Journal, 37, 108.

Gillespie L D, Gillespie W J, Robertson M C, Lamb S E, Cumming R G, Rowe B H, 2003. Interventions for preventing falls in elderly people (Cochrane Review). In: The Cochrane Library, Issue 4, 2003 (Wiley: Chichester).

Haegerstrom-Portnoy G, Schneck M E and Brabyn J A, 1999. Seeing into old age: vision function beyond acuity. Optometry and Vision Science, 76, 141-158.

Haslam R A, Sloane J, Hill L D, Brooke-Wavell K and Howarth P, 2001. What do older people know about safety on stairs? Ageing and Society, 21, 759-776.

Healy J and Yarrow S, 1998. Safe at Home? Views of Professionals on Preventing Accidents in the Home among Older People (Health Education Authority: London).

Howarth P A, 2005. Assessment of the visual environment. In: Evaluation of Human Work (edited by Wilson J R), $3^{\text {rd }}$ edition, pp 663-661. 
Howarth P A and Bullimore M A, 2005. Vision and visual work. In: Evaluation of Human Work (edited by Wilson J R), $3^{\text {rd }}$ edition, pp 573-604.

Lord S R, Sherrington C and Menz H B, 2001. Falls in Older People: Risk Factors and Strategies for Prevention (Cambridge University Press: Cambridge).

Masud T and Morris R O, 2001. Epidemiology of falls. Age and Ageing, 30-S4, 3-7.

Nagata H, 1993. Fatal and non-fatal falls - a review of earlier articles and their developments. Safety Science, 16, 379-390.

National Institute for Clinical Excellence (NICE), 2004. Falls: the assessment and prevention of falls in older people (National Institute for Clinical Evidence: London), Clinical Guideline 21, ISBN 1-84257-829-4.

Pauls J L, 1985. Review of stair-safety research with an emphasis on Canadian studies. Ergonomics, 28, 999-1010.

Pauls J L, 1991. Safety standards, requirements, and litigation in relation to building use and safety, especially safety from falls involving stairs. Safety Science, 14, 125-154.

Prudham D and Evans J G, 1981. Factors associated with falls in the elderly: a community study. Age and Ageing, 10, 141-146. 
Roys M, 2001. Serious stair injuries can be prevented by improved stair design. Applied Ergonomics, 32, 135-139.

Smith D B D, 1990. Human factors and ageing: an overview of research needs and application opportunities. Human Factors, 32, 509-526.

Smith D W E, Snell J, Brett A W, Jackson F W, Straker J K and Ulmer M E, 1994. A study of stairs in the housing of independently-living elderly people. International Journal of Aging and Human Development, 39, 247-256.

Startzell J K, Owens D A, Mulfinger L M and Cavanagh P R, 2000. Stair negotiation in older people: a review. Journal of the American Geriatrics Society, 48, 567-580.

Templer J, 1992. The Staircase (MIT Press: Massachusetts).

Tinetti M E, Speechley M and Ginter S F, 1988. Risk factors for falls among elderly persons living in the community. New England Journal of Medicine, 319 (26), 1701-1707.

Wright F and Whyley C, 1994. Accident Prevention and Risk-taking by Elderly People: the Need for Advice (Age Concern Institute of Gerontology: London), ISBN 1-872342-11-6. 